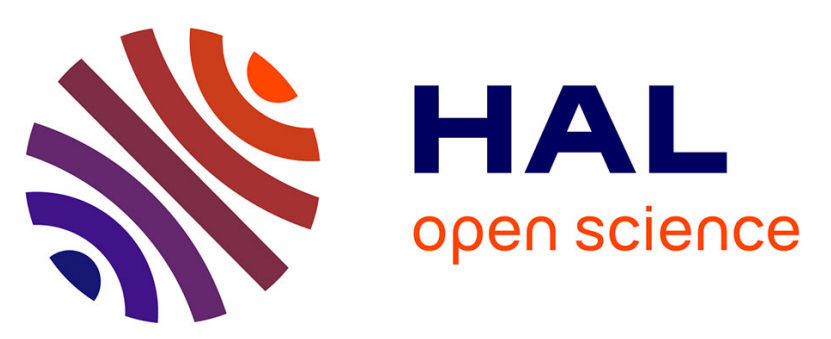

\title{
Finding Teammates Who Are Not Prone to Sucker and Free-Rider Effects: The Protestant Work Ethic as a Moderator of Motivation Losses in Group Performance
} Susanne Abele, Michael Diehl

\section{- To cite this version:}

Susanne Abele, Michael Diehl. Finding Teammates Who Are Not Prone to Sucker and Free-Rider Effects: The Protestant Work Ethic as a Moderator of Motivation Losses in Group Performance. Group Processes and Intergroup Relations, 2008, 11 (1), pp.39-54. 10.1177/1368430207084845 . hal00571675

\section{HAL Id: hal-00571675 \\ https://hal.science/hal-00571675}

Submitted on 1 Mar 2011

HAL is a multi-disciplinary open access archive for the deposit and dissemination of scientific research documents, whether they are published or not. The documents may come from teaching and research institutions in France or abroad, or from public or private research centers.
L'archive ouverte pluridisciplinaire HAL, est destinée au dépôt et à la diffusion de documents scientifiques de niveau recherche, publiés ou non, émanant des établissements d'enseignement et de recherche français ou étrangers, des laboratoires publics ou privés. 


\title{
Finding Teammates Who Are Not Prone to Sucker and Free-Rider
} Effects: The Protestant Work Ethic as a Moderator of Motivation Losses in Group Performance

\author{
Susanne Abele \\ Erasmus University Rotterdam \\ Michael Diehl \\ University of Tuebingen
}

\begin{abstract}
This study examined whether differences in the endorsement of the 'Protestant Work Ethic' (PWE) are related to motivation losses in group work. Three factors were derived from male student scores on the Mirels-Garrett Protestant Work Ethic Scale, Ho's Australian Work Ethic Scale and a scale designed to assess preferences for reward distributions: instrumental value of work, ethical value of work and normative value of equity. The study assessed motivation loss in two situations; one designed to promote free-rider effects and another designed to promote sucker effects. Results showed that the sucker effect was moderated by all three factors but in qualitatively different ways whereas the free rider effect was not strongly moderated by any of the PWE factors.
\end{abstract}

KEYWORDS group productivity, motivation losses, Protestant Work Ethic

MANY important tasks cannot be completed by single individuals, but can only be accomplished by groups. Many tasks in organizations require members of teams to pool their individual contributions in order to reach the group goal (e.g. Antoni, 1994). However, teamwork does not always work out as intended. In some instances, the group product is satisfying; in other instances, the group is far from achieving their productive potential.

The failure of groups to realize their potential group productivity has been thoroughly investigated and is a well established finding. Decreased productivity can be the result of coordination losses, but it is also a result of effort reduction stemming from motivation losses

\footnotetext{
$\overline{\text { Author's note }}$

Address correspondence to Susanne Abele, Miami University, Department of Psychology, 100 Psychology Building, 90 N Patterson Ave, Oxford, Ohio, 45056, USA [email: abeles@muohio.edu]
} 
(Latane, Williams, \& Harkins, 1979; Steiner, 1972). One proposed reason for motivation losses is that individuals might realize that their contribution cannot be identified and thus evaluated (Harkins \& Jackson, 1985). Furthermore, group members may perceive their contributions as dispensable and hence reduce their effort while free-riding on the contributions of the others (Kerr \& Bruun, 1983). These explanations assume that the basic motivation of each individual cannot be intrinsic to working per se or to maximize the group's utility. It is rather assumed that the basic motivation of each individual consists in maximizing individual utility, hence maximizing the individual input-output ratio, an assumption underlying neoclassical economics.

Group work can be viewed as a social dilemma (Kerr, 1983) inasmuch as the strategy 'not to contribute to the group product' dominates the strategy 'to contribute', no matter what the other group members are doing. However if no one contributes, the collective is worse off as the group does not produce. In other words, group members have an incentive to defect as long as their contributions are additive and the members' main aim is to achieve a maximal individual outcome. But pursuing that strategy is not conducive to group productivity, and hence in conflict with the collective interest.

The products of groups have an enormous significance in our lives. In the past, when manufacturing was the predominant industry, the pooling of physical effort was important. More recently, as more jobs are generated in the knowledge industry, joint effort in cognitive tasks has gained in importance. Examples of collective effort on cognitive tasks include writing a joint report, developing a commercial computer program, or operating an air traffic control system. In addition, globalization is leading to faster moving societies and changing traditional values. Values like modesty, diligence and honesty have the taste of being old-fashioned, while self-actualization, pursuing a career and cultivating a healthy narcissism are on the agenda (e.g. Hogan \& Blake, 1996). If the spirit of the 21st century is dominated by pursuing one's own individual goals, and on the other hand, team work is important, then an issue arises as to what types of people can work effectively in teams. In the current research, we address the issue of whether all individuals are equally inclined to loaf in collective work, or whether there is a way to differentiate systematically team workers from team loafers. After all, when team work is so important, a way to identify those who still exert effort in groups would seem important for all concerned. Before we turn to the specific question of what motivates people to contribute to a group product, we will briefly summarize the social psychological explanations for reduced group productivity.

\section{Motivation losses in group work}

Since the discovery and analysis of the Ringelmann effect (see Ingham, Levinger, Graves, \& Peckham, 1974; Kravitz \& Martin, 1986; Moede, 1927), we know that group work compared to individual work often results in productivity losses. Latane et al. (1979) showed that the decreased productivity is caused both by coordination loss and by effort reduction. They interpreted the effort reduction as a result of motivation losses and called it 'social loafing'. With emerging research the phenomenon of motivation losses in groups has been given different labels depending on the circumstantial conditions. Social loafing stems from the realization that the individual contribution cannot be identified and thus evaluated (Harkins \& Jackson, 1985). The potential for evaluation can come from other group members, external sources (e.g. the experimenter), or from the possibility for self-evaluation, and any of these can eliminate the effect (Harkins \& Szymanski, 1989; Szymanski \& Harkins, 1987). Free-riding stems from the perception that the individual's contribution is dispensable, even if it is identifiable and appraisable (Kerr \& Brunn, 1983; for a detailed analysis of task type and possible motivation losses in the framework of social dilemmas, see also Arnscheid, Diehl \& Stroebe, 1997). The suckereffect results from the perception that others are free-riding on one's contributions or efforts (Orbell \& Dawes, 1981). In this case it is the 
potential of the averseness of this role, which makes the individual reduce his/her effort. Kerr (1983) argues that the violation of certain social norms like the equity norm, the norm of reciprocity and the norm of social responsibility make the sucker role uncomfortable. In the last decade motivation losses in group performance have been linked to general theories of motivation (Karau \& Williams, 1993; Shepperd, 1993; Shepperd \& Taylor, 1999).

The proposed underlying mechanism for the free-rider effect and social loafing are based on the assumption that individuals' main driving force is to maximize individual outcomes while minimizing input. The proposed underlying mechanism for the sucker-effect is, in a sense, distinct from the other two, as it is based on the assumption that behavior can also be driven by other motives and needs like feeling socially equal and accepted. An obvious question is whether other motives, as for instance seeing work as something valuable per se, may play important roles in group work also.

\section{What moderates motivation losses in group work}

Karau and Williams' (1993) meta-analytic review concludes that motivation losses in group work is a robust phenomenon which generalizes across tasks and populations. Above we have briefly mentioned variables that play a role in the underlying processes of motivation losses in groups. Among those, evaluation potential, expectations of coworker performance, task meaningfulness and culture were found to have a consistent impact (Karau \& Williams, 1993).

Moreover, individual differences have also been shown to moderate motivation losses in groups. Need for cognition refers to the tendency to engage in and enjoy effortful cognitive endeavors (Cacioppo \& Petty, 1982). Smith, Kerr, Markus, and Stasson (2001) demonstrated that the need for cognition can moderate motivation losses in group work: individuals high in need for cognition worked equally hard on a vigilance task, regardless of whether they were working collectively or coactively. Individuals low in need for cognition, however, exerted considerably less effort when working collectively compared to working coactively.

Hart, Karau, Stasson, and Kerr (2004) showed that people high in achievement motivation exerted equal effort whether they were working coactively or collectively and whether they expected the other person to exert high or low effort. However, people low in achievement motivation reduced their effort most when working collectively with somebody from whom they expected high effort. Hence, apparently they reduced their effort when they perceived their contribution as dispensable and not identifiable. However, what is not clear in their study is how participants interpreted the allegedly predicted effort of their team member. When induced to expect low effort, participants received the message that their team partner found the task very interesting but was not going to exert much effort on it. This message is ambiguous. Participants could have attributed the reduced effort of their partner to their lack of willingness or of capability. Neither of these attributions is compelling. On the one hand, why would somebody reduce effort on a task that she/he finds interesting? On the other hand, why would lack of ability lead to a reduction of effort? Moreover, the source of attribution for the reduced effort plays an important role in social loafing. Reduced input from a team member due to lack of ability evokes quite different reactions than reduced effort due to a lack of willingness (Kerr, 1983).

As noted above, previous research has shown that need for cognition and achievement motivation moderate reduction of effort in collective work. However, effects of these moderators would not differ depending on whether a partner's reduced effort stemmed from unwillingness or inability. People high in need for cognition or achievement motivation would sustain their effort regardless of the reason for the partner's reduced effort. In these cases, the enjoyment of the task (need for cognition) or the desire to achieve are not dampened by a partner's lack of motivation or ability. However, beliefs regarding the value of work and the importance of equity should moderate one's reactions to a partner and her/his reasons for reducing effort. 


\section{The Protestant Work Ethic}

In 1905 Max Weber published 'The Protestant ethic and the spirit of capitalism'. The basic idea was that the Protestant ethic was an important factor in the economic success of Protestant groups in the early stages of capitalism. Worldly success was interpreted as a sign of righteousness and therefore vigorously pursued. Since Weber, anthropologists, economists, sociologists, historians and psychologists have been interested in the issue of the Protestant Work Ethic (PWE). Psychologists were not concerned with whether Weber was right or wrong but translated the concept into an individual difference construct.

McClelland (1961) was the first to use the concept of PWE within psychology. His explanation for the association between Protestantism and capitalism was the following. Parents, who have internalized Protestant values, reared their children in ways that foster independence, rationality and delay of gratification. Instilling these values produces children with a high achievement motivation, and people with a high achievement motivation are very likely to contribute to the expansion of business. He subsumed the concept of PWE under need for achievement. Placing PWE in this conceptual context has been criticized because it emphasizes only the 'hard work-aspect' of the work ethic and leaves out other aspects. Nonetheless, the idea that high achievement motivation is a relatively stable disposition which has its roots in early socialization led others to construe PWE beliefs as an individual difference of conceptual interest. The research focus shifted from the etiology of the PWE to the measurement of the construct and to its relationships to behavior patterns and other belief systems. Several selfreport measures were developed (e.g. Blood, 1969; Buchholz, 1976; Goldstein \& Eichhorn, 1961; Hammond \& Williams, 1976; Ho, 1984; Mirels \& Garrett, 1971; Ray, 1982). Using these measures, PWE has been shown to correlate with behaviors and other constructs. Persons with a high PWE are industrious, ambitious, hard working and intrinsically motivated (Furnham, 1990a), stemming from the attitude that work will and should pay off. They tend to have an internal locus of control in matters that are linked to work (Lied \& Pritchard, 1976) and are not easily affected by external factors. Their behavioral orientation in a free-choice period is to work equally hard on the task regardless of the performance feedback (Furnham, 1990a). Moreover, they are inclined to apply an equity norm, as opposed to an equality norm, in deciding how to distribute a resource (Greenberg, 1978).

Equity norm refers to a proportional inputoutput relation. People perceive a distribution as fair when their own ratio of inputs to outputs equals the input-output ratio of others. Put differently, according to equity norm, rewards should be distributed in direct proportion to the effort each group member exerts (Adams, 1965; Walster, Berscheid \& Walster, 1973). In contrast to that, the equality norm does not focus on the input-output relation in determining whether justice or injustice is perceived, but merely on an equal size of the output. Hence, the equality norm would suggest an equal distribution of rewards irrespective of inputs (Homans, 1958, 1961).

\section{The relationships among components of PWE, free-riding and being the sucker}

The purpose of the current study is to investigate the PWE as a moderator of motivation losses in group work. Heaven (1989) as well as Furnham (1990b) delivered empirical evidence that the global construct 'PWE' consists of several components. Thus different components might be responsible for the behavioral correlates and associations with other personality constructs and attitudes, which were described above. For example, a high work ethic is associated with a preference for the equity norm and the belief in the instrumental value of work ('work should and does pay off') and the belief in the ethical value of work ('it is ethical to be occupied with work'); whereas people with a low work ethic are extrinsically motivated and prefer the equality norm when asked to divide a reward, and do not believe in the ethical value of work (Furnham, 1990a; Greenberg, 1978). The implication is 
that PWE is a global construct that includes distinct components: a belief in the long-range instrumental value of work, a belief in the ethical value of work and a preference for equity (as opposed to equality) in the distribution of resources.

These components-the preference for an equity norm and beliefs about the instrumental and ethical value of work-are relevant to the reactions one has to others' efforts in collective work. The free-riding effect occurs, when individuals realize that their contribution to the group product is dispensable while they can nevertheless benefit from the group product. That is, the free-rider effect is due to maximizing the individual cost-benefit ratio by reducing effort. On the one hand, for people who have internalized the ethical value of work and the conviction that work has a long-range instrumental value, working hard should have a high value regardless of the immediate outcome. On the other hand, people who subscribed to equity principles should also not reduce effort at the expense of others. Thus, all of the components of PWE should immunize one against the tendency to free ride. Therefore participants with a high PWE should not show the free-rider effect, whereas participants with a low PWE should show the free-rider effect.

The sucker-effect occurs when individuals perceive the danger that others may free-ride on their contributions. Thus, a potential violation of the equity norm is responsible for motivation loss. In group work, the reward system is often such that a group product is divided equally among all group members; hence, the equality principle is followed in the distribution of reward for performance. As a consequence, once group members perceive that others are free-riding, one way to prevent violation of the equity norm is to reduce one's own contributions. Thus, people who score high on the equity component of PWE should show the suckereffect to a higher extent than persons with a low PWE equity score. However, if the belief in the instrumental values of work prevails, persons with a high work ethic should show the sucker effect to a lesser extent. That is, belief in the long-range instrumental value of work should, as in the free-rider case, make one less responsive to the immediate outcomes and thus less concerned with the possibility that others are free riding. The implications of the ethical factor are less clear, however. On the one hand, if one believes that hard work is ethical, then one should work hard regardless of what others are doing. On the other hand, sucker-effects are a reaction to others' actual or anticipated failures to work hard-that is, to behave in an unethical manner. When framed this way, continuing to work hard in the face of others' 'laziness' rewards those who are undeserving. Thus, those who subscribe to the ethical value of work may be particularly sensitive to being the 'sucker'. In sum, concerning the sucker-effect, contrasting predictions can be derived from the concept of PWE. Understanding the relationship between PWE and susceptibility to the sucker-effect requires that the components of PWE (namely, endorsement of the instrumental value and the ethical value of work, and preference for equity norm) be measured separately.

\section{Hypotheses}

All three components of PWE are expected to have consistent relationships to free-riding. That is, free riding should not occur (or be reduced) for participants with high PWE scores whereas the effect should be observed strongly for participants with low PWE scores.

The predictions regarding the relationships among PWE components and the sucker-effect are more complicated. Two countervailing hypotheses concerning the relationship between PWE and the sucker effect are considered. First, people who score high on the equity component of PWE should exhibit the sucker effect whereas those who score low should not. Second, if belief in the long-range instrumental value of work overrides concerns about being the sucker, the reverse pattern should occur: people who score low in the instrumental component of PWE should exhibit the sucker-effect whereas those who score high should not. Finally, it is not clear how people who subscribe to the ethical value of hard work will react to being a 'sucker'. If those who believe that hard work is good focus on the 
implications for themselves, they should not exhibit the sucker effect. However, if they focus on the implications for the ethics (and perhaps deservingness) of others, then they should avoid being the sucker because doing so benefits the 'undeserving' at one's own expense.

\section{Method}

\section{Overview}

In order to test the research hypotheses, a situation was designed that permitted free-riding, and another situation was designed that made participants vulnerable to the sucker-effect. Also included were two corresponding control conditions. Participants worked in dyads on a potentially divisible task.

In the free-rider condition, participants were led to believe that their partner was capable of the task by the initial feedback on the task performance. In the free-rider control condition, participants performed the task individually.

In the sucker effect condition, hereafter referred to as the sucker condition, the partner of the participant is portrayed as capable by the initial feedback on task performance. The feedback after the first three trials revealed that the team did quite well on the task, but that the participant's contribution consistently exceeded the 'partner's' contribution. The 'partner' of the participant was a confederate of the experimenter. In order to have the participants really attribute the 'partner's' smaller contribution to his reduced effort and not to lower ability, the confederate displayed boredom by scripted behavior. In the sucker effect control condition, hereafter referred to as the sucker control condition, the participant's contribution exceeded the 'partner's' contribution. But here the participant was led to believe by the initial task performance feedback that their partner's task ability was low. During the initial trials, the confederate commented on the difficulty of the task.

\section{Participants and design}

Eighty male students from University College London participated in the experiment. Because of the sex difference in the suckereffect (Kerr, 1983) only males were included.
Participants were randomly assigned to one of the four experimental conditions (free-rider, free-rider control, sucker or sucker control). Thus, the design was a four independent group design.

\section{Measurement of PWE}

The endorsement of the PWE was assessed with the Protestant Work Ethic Scale from Mirels \& Garrett (1971) and the Australian Work Ethic Scale from Ho (1984). Despite the theoretical inclusion of the equity/equality norm in the concept of PWE as a variable of individual differences, these scales do not include items that measure directly a preference for equity or equality. Therefore, nine additional items were created to assess the degree to which participants endorse the equity norm. Examples of such items are: 'The trouble with giving people equal rewards for work is that they very rarely work equally hard' or 'When a task is completed by a team there is nothing wrong with distributing the reward equally regardless of unequal input'.

\section{Task}

The task that the participants performed in three trials was the ' $d 2$ ' concentration test (Brickenkamp, 1994). In this test, participants are confronted with a sheet full of the letters ' $d$ ' and 'p' which have one to four lines above or beneath them. The task is to work through the lines of letters and cross out every ' $d$ ' that has two lines with it. To provide a rationale for participants to complete this task in teams and to deflect their attention from our interest in individual performance in collective endeavors, the following cover story was presented:

This study is about how to design the task of manually checking transfer slips most efficiently. In most instances one fills in forms nowadays using the computer. However, some service providers, like banks, are still obliged to offer other possibilities for clients to hand in forms. Service providers let clients also use forms, which can be filled in by hand, but can later be read by a computer. People are instructed how to fill in these forms, so that the computer can read them, but still a given percentage cannot be read by the computers. When the computers read the forms, the information is translated into a code. This code then appears on a screen, and consists 
of signs and abnormalities. The signs represent information from the transfer slip that could be read properly, whereas the abnormalities stem from information that could not be read properly. Somebody has to detect the abnormalities, which demands a continuously high concentration and is a boring task. A short period of inattention will lead to a greater amount of undetected abnormalities, which will be noticed in the succeeding processing. The study tests whether sharing the task so that the code would come up on two screens has an impact. Another feature that the study addresses is whether and how much feedback and feedback frequencies have an impact on performance. Hence, participants will be working on a task, where they have to detect abnormal signs in a list of abnormal and normal signs (they were doing this either with another person or alone) and will be given feedback in regular frequencies.

\section{Procedure}

After arrival participants were asked to complete the PWE questionnaires, which were said to be part of a different research project. They were then told the alleged purpose of the study before they were randomly assigned to one of the four conditions. With the exception of the free-rider control condition, participants were told that they would work at the task as a cooperative team and that their performances would be summed and they would be rewarded for their combined performance regardless of their individual contributions. Participants were guaranteed $£ 2$ as a reward and they were told that they could earn up to $£ 3$ depending on their combined performance. £3 was worth approximately US $\$ 5$. Eventually everybody was paid £3. Participants were then made familiar with the requirements of the task by practicing on a line of letters. During the actual experimental trials participants were wearing headphones. The command to start was given via these headphones. Furthermore, during the trials there was office noise in the room in order to prevent the participants from overhearing each other's speed.

The first trial lasted for one minute and participants were told that this trial was meant to assess their initial ability. The second to the fourth trials lasted for two and a half minutes each. The experimenter left the room while the 'teams' were actually working on the task. Behavior in the room could be monitored through a glass window in the door. After each trial the experimenter returned, took the sheets from the participants and allegedly scored them in the same room.

Participants were told that their feedback would compare their performance to the average performance by other participants. In all experimental conditions participants were given the feedback after the first trial in which their own performance, which was supposedly the initial ability, was $20 \%$ above average. In the sucker condition and the free-rider condition they were told that their partner's performance was $20 \%$ above average as well, whereas in the control condition to the sucker-effect the performance feedback for the partner was $5 \%$ below average.

After the first trial in the sucker condition, the confederate yawned and stretched and started to lean back with his chair while the sheets were corrected. After the second trial he again leaned backwards and began to drum with his fingers on the table. The performance feedback then revealed a combined result around $20 \%$ above average and a contribution of the participant to the total of about $60 \%$. After the third trial the confederate mumbled to himself 'it's getting boring', while the experimenter was still outside the room. The performance feedback for this trial then again revealed a combined result that was $20 \%$ above average, to which the participant had again contributed more than $60 \%$.

In the sucker control condition the confederate said after the first trial, 'I can't tell them apart'. After the second trial he moaned and said to himself 'it is really difficult'. The combined result was said to be $20 \%$ above average and the contribution of the participant about $60 \%$. After the third trial the confederate said 'not easy' while handing his sheet over to the experimenter. Feedback for this trial then revealed the same result as for the second trial.

In the free-rider condition participants were told after the second and third trials that they together achieved $20 \%$ above average; no information was given concerning the individual 
contributions to the team performance. In the free-rider control condition participants were given the feedback that they achieved about $20 \%$ above average after each trial.

Feedback was never provided after the fourth trial in any of the four experimental conditions. After the fourth trial, participants were asked to complete a questionnaire that functioned as a manipulation check. Participants were then debriefed, thanked and paid.

\section{Results}

\section{The PWE}

In order to disentangle the components of the global construct a principal component factor analysis with varimax rotation was conducted using all of the items from the questionnaires. A scree plot indicated the presence of three factors. These three factors accounted for $38.6 \%$ of the variance. The first factor accounted for $13.23 \%$ of the variance. Items loading high on this factor portray the attitude that work has a moral value. It was therefore called the Ethical Factor. The second factor explained $12.9 \%$ of the variance. Items loading high on this factor capture the notion that work should and will pay off. It was therefore called the Instrumental Factor. The third factor explained $12.5 \%$ of the variance, and items loading high on this factor measure the attitude to the equity principle. This factor was called the Equity Factor. Examples for items loading high on the respective factors can be found in the Appendix. Factor scores were computed to be used later as a measure of individual differences on the three dimensions.

\section{Analysis of the performance data}

Four participants had to be excluded from the analysis; one had suspicions about the confederate and the other three did not complete the task properly. Table 1 reveals the mean raw performance scores in all four conditions for the four trials. Raw performances are the number of all correctly marked signs minus all false positives (signs marked which should not have been) and misses (unmarked signs that should have been marked prior to the last correctly marked sign).

The primary dependent variable was performance on the fourth trial. As depicted in Table 1, scores in the fourth trial in the free-rider condition $(M=282.26)$ and in the sucker condition $(M=279.47)$ were lower than in the free-rider control condition $(M=316.8)$ and in the control condition sucker-effect $(M=295.8)$. A one-way analysis of covariance was performed, with the performance in the fourth trial as a dependent variable, and the performance on the first trial as a covariate. The first trial was used as a covariate in order to control for individual differences in performance before the introduction of the experimental manipulations and hence reduce error variance. There was a main effect of the condition $(F(3,71)=3.2$, $p<.028)$. Also the effect of the covariate was significant $(F(1,71)=58,7, p<.001)$. Table 2 contains the mean performances adjusted for the covariate.

Two contrasts were calculated to test for the free-rider effect and the sucker-effect, respectively. The comparison for the free-rider to the free-rider control was significant $(F(1,67)=5.67$, $p<.05)$. The comparison of the sucker effect

Table 1. Number of signs participants managed to work on in the different conditions

\begin{tabular}{lcccc}
\hline & $\begin{array}{c}\text { Condition 1: } \\
\text { Free-rider effect }\end{array}$ & $\begin{array}{c}\text { Condition 2: } \\
\text { Control free-rider effect }\end{array}$ & $\begin{array}{c}\text { Condition 3: } \\
\text { Sucker-effect }\end{array}$ & $\begin{array}{c}\text { Condition 4: } \\
\text { Control sucker-effect }\end{array}$ \\
\hline 1. Trial ${ }^{\mathrm{a}}$ & $107.58(17.52)$ & $115.2(12.53)$ & $106.41(17.69)$ & $104.5(18.78)$ \\
2. Trial & $273.79(32.69)$ & $287.75(31.18)$ & $271.24(43.16)$ & $259.55(39.99)$ \\
3. Trial & $280.89(35.35)$ & $301.95(30.07)$ & $276.41(39.38)$ & $279.55(41.42)$ \\
4. Trial & $282.26(40.14)$ & $316.8(32.58)$ & $279.47(43.53)$ & $295.8(41.58)$ \\
\hline
\end{tabular}

a Please note that the first trial lasted for one minute only, while the others lasted for 2.5 minutes.

Note: Table entries are means with standard deviations in parentheses. 
Table 2. Adjusted means in Trial 4

\begin{tabular}{lcccc}
\hline & $\begin{array}{c}\text { Condition 1: } \\
\text { Free-rider effect }\end{array}$ & $\begin{array}{c}\text { Condition 2: } \\
\text { Control free-rider effect }\end{array}$ & $\begin{array}{c}\text { Condition 3: } \\
\text { Sucker-effect }\end{array}$ & $\begin{array}{c}\text { Condition 4: } \\
\text { Control sucker-effect }\end{array}$ \\
\hline 4. Trial & $283.74(6.75)$ & $306.19(6.72)$ & $282.81(7.15)$ & $302.17(6.63)$ \\
\hline
\end{tabular}

condition to its control revealed a significant sucker effect $(F(1,67)=3.978, p<.05)$.

\section{Sucker and free-rider effects and PWE}

A regression analysis was conducted using only participants from the sucker control condition and the sucker effect condition. The regression model used performance on the fourth trial as the dependent variable and trial 1 performance, sucker effect conditions and scores on the original PWE scale as predictors. Also included was an interaction term of condition by PWE score. All predictors were centered before the regression was conducted. The effect of the trial 1 performance and sucker condition were significant, confirming the results from the foregoing covariance analysis. The interaction of sucker condition by score on PWE scale was only marginally significant $(t(32)=1.58, p>.12)$. Thus the sucker effect was marginally moderated by people's score on the global PWE scale.

A regression analysis was conducted using only participants from the free-rider condition and the free-rider control condition. The regression model used performance on the fourth trial as the dependent variable and trial 1 performance, free-rider effect conditions and scores on the original PWE scale as predictors. Also included was an interaction term of condition by PWE score. All predictors were centered before the regression was conducted. The effect of the trial 1 performance and free rider conditions were significant, confirming the results from the covariance analysis. The interactions with the PWE score was not significant $(t(34)<1, n s)$.

\section{Sucker-effect and PWE factors}

For each of the PWE factors, a regression analysis was conducted using only participants from the sucker control condition and the sucker-effect condition. The regression model used performance on the fourth trial as the dependent variable and trial 1 performance, sucker-effect conditions and factor scores as predictors. Also included was an interaction term of condition by respective factor score. All predictors were centered before conducting the regression. In all the regressions the effect of the trial 1 performance and sucker condition were significant, confirming the results from the covariance analysis. The interaction of sucker condition by factor score was significant for all components: instrumental factors $(t(36)=2.01$, $p>.05)$, ethical factor $(t(36)=2.19, p<.036)$ and equity factor $(t(36)=2.06, p<.048)$. Thus the sucker-effect was different for people who scored high and low on all of the PWE factors.

To better understand the nature of the interactions of PWE factors and the suckereffect, estimated means for people scoring one standard deviation above and one standard deviation below the mean on each factor were obtained using the regression model. These estimated means are plotted for participants in the experimental sucker and sucker control conditions in Figures 1 to 3.

Participants, who endorsed the idea that work should and will pay off, worked almost as hard in the sucker control condition $(M=285.09)$ as they did in the sucker experimental condition $(M=281.69)$. But participants who did not see work as something that should and will pay off worked harder when working with somebody who was contributing less because of ability $(M=306.44)$, than when working with someone who contributed less due to lack of effort $(M=272.05)$. Thus, people endorsing the instrumental value of work were not affected by being the sucker. They seemed to focus more on their part of the work even if the other was not working hard. People who believed less in the long-range instrumental value of work worked harder when their partner was incapable than when he was unwilling to exert effort. 


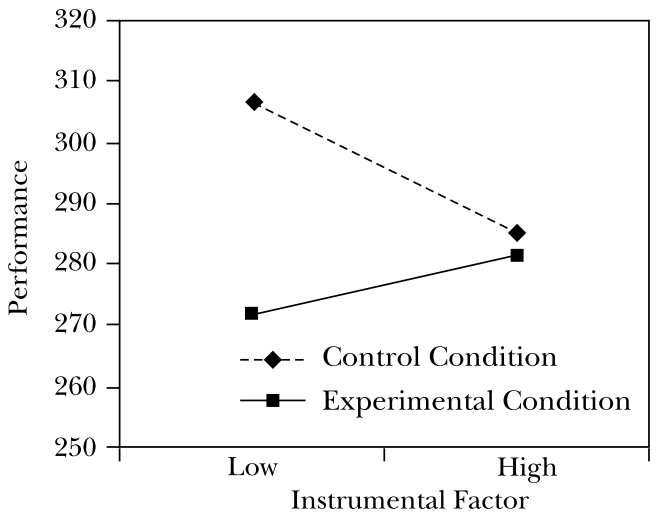

Figure 1. Sucker-effect moderated by individual differences in the belief in the instrumental value of work.

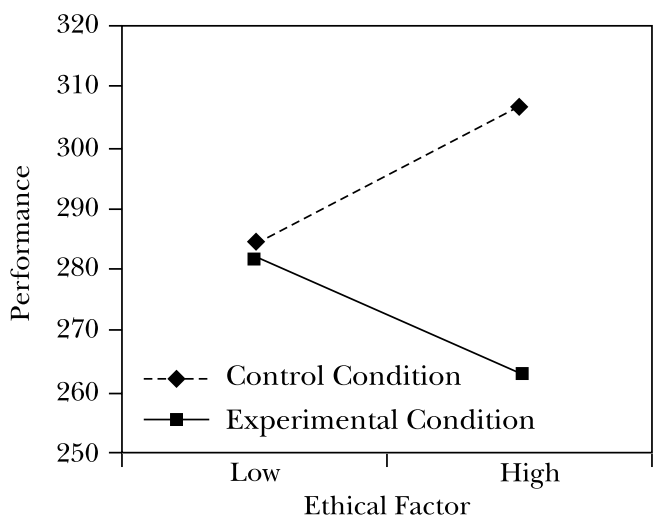

Figure 2. Sucker-effect moderated by individual differences in the belief in the ethical value of work.

Endorsement of the ethical value of work and of equity produced similar patterns in the sucker conditions. When their partner was incapable, participants who endorsed the ethical value of work $(M=306.84)$ and who endorsed the equity principle $(M=310.32)$ worked harder than those who did not subscribe to the ethical value of work $(M=263.18)$ and to the principle of equity $(M=271.4)$. In contrast, participants who did not endorse the ethical value of work and participants who subscribed to the equality principle exerted about the same effort regardless of whether their partner was performing poorly due to inability or due to

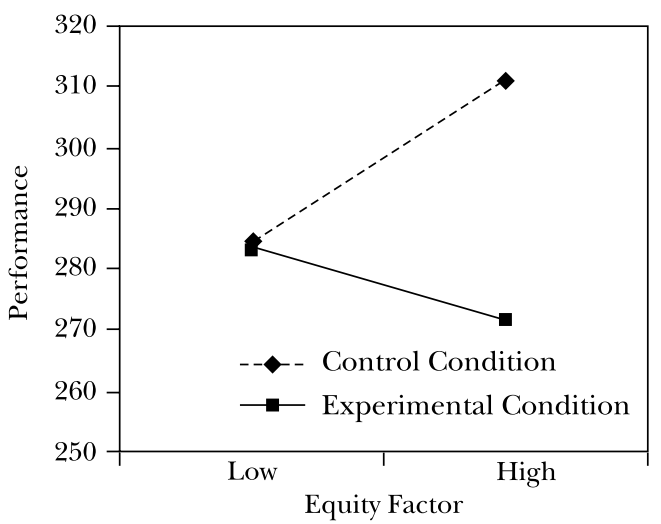

Figure 3. Sucker-effect moderated by individual differences in the belief in equity.

lack of trying. So apparently belief in the ethical value of work and adherence to the equity principle led participants to compensate for an incapable partner but to avoid being a sucker.

\section{Free-rider effect and PWE factors}

For each of the PWE factors, a regression analysis was conducted using only participants from the free rider condition and the free rider control condition. The regression model used performance on the fourth trial as the dependent variable and trial 1 performance, free rider effect conditions and scale score as predictors. Also included was an interaction term of condition by scale score. All predictors were centered before the regression was conducted. In all the regressions the effect of the trial 1 performance and free rider conditions were significant, confirming the results from the covariance analysis. The predicted interaction of free-rider condition by instrumental scale score was only marginally significant $(t(38)=1.49$ $p<.07$, one-tailed). The interactions with the equity and ethical scale were not significant. Thus the free-rider effect was marginally different only for people who scored high and low on the instrumental component of PWE. The estimated means for people scoring one standard deviation above and one standard deviation below the mean on the instrumental factor were obtained using the regression model. These estimated means are plotted for participants 
in the experimental free-rider and free rider control conditions in Figure 4.

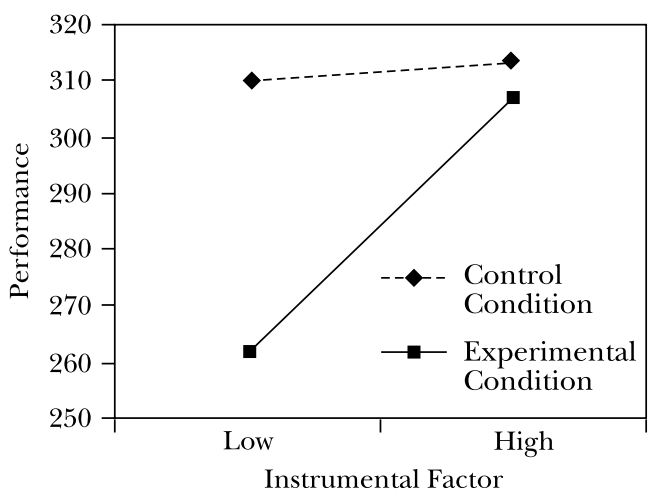

Figure 4. Free-rider effect by individual differences in the belief in the instrumental value of work.

Participants who believed in the instrumental value of work showed no difference in performance in the free rider control condition $(M=312.82)$ and the free-rider experimental condition $(M=307.36)$. But participants who did not believe in the instrumental value of work were affected by the situational circumstances in their effort exertion. When working alone, they worked harder $(M=309.66)$ than when working as a team $(M=262.52)$ with an allegedly skilled person and individual contributions were not identifiable.

\section{Discussion}

The purpose of this study was to investigate the moderating effects of attitudes toward work, as embodied in the global construct of the PWE, on motivation losses in performance groups. We distinguished two types of motivation loss which we suggest involve distinctly different psychological processes. More specifically, the suckereffect is a reaction to reduced effort by others in collective work and, as the name implies, to the potential of one's own effort being exploited by others. The free-rider effect is the robust tendency to reduce effort in collective work when individual contributions are not identifiable. Our experimental setup induced both suckerand free-rider effects. When participants were working with another individual and their individual contributions were combined and unidentifiable, they produced less than when they thought they were working alone-the classic free-rider effect. When they were working with another person whose output was relatively low, they produced less when they thought the other person was not trying than when they thought the other person was not capable-the classic sucker-effect.

Our purpose was to examine whether components of PWE moderate the inclinations to reduce effort in the free-riding and sucker conditions. Based on past work with PWE (e.g. Furnham,1990b; Heaven, 1989), we anticipated that the global construct was a combination of at least three components: belief that work will be rewarded (instrumental component), belief that hard work is a marker of righteousness (ethical component) and belief that people ought to be rewarded equitably for their work (equity component). We constructed the gobal measure of PWE from items taken from Mirels and Garrett (1971) and Ho and Lloyd (1984) and added additional items designed to measure more preferences for equity in the distribution of resources. We factor analyzed responses to items from this global measure and obtained distinct factors that corresponded to the anticipated components of belief in the ethical value of work, the instrumental value of work and the equity principle.

Even though they are distinct, conceptually and empirically, the factors are strongly correlated with the traditional measures of PWE. For example the instrumental factor correlated .85 with the Ho and Lloyd's (1984) PWE scale and .48 with the PWE scale used by Mirels and Garrett (1971). The ethical factor also correlated strongly with the Mirels and Garrett scale $(r=.74)$ but modestly with the Ho and Lloyd measure $(r=.27)$. The equity factor, not surprisingly given that it consisted largely of items not contained in these traditional measures, correlated modestly both with the Mirels and Garrett scale $(r=.38)$ and with the Ho and Lloyd scale $(r=.27)$.

We expected that these components of PWE would moderate free-riding and sucker- effects in different ways. Concerning the sucker-effect 
and a potential moderating role of the PWE, we had two contrasting hypotheses. On the one hand, we speculated that people high in the instrumental value component of PWE would not show the sucker-effect because of their belief that hard work pays off in the long run. On the other hand, people who subscribe strongly to an equity norm should show the sucker-effect in that they would react to the violation of the equity norm in a situation where a partner is, by choice, coasting. Thus, we did not expect that the global measure of PWE would moderate the sucker-effect and it did not.

Our expectation regarding the moderating influence of the instrumental component on the sucker-effect was confirmed. Participants who believed in the long-range instrumental value of work were not affected by the reasons for their partner's low output. Whether he contributed less than the participant due to lack of ability or to lack of motivation did not seem to matter to them. In contrast, participants who did not endorse the instrumental value of work exerted more effort when their partner was incapable rather than lazy. Somewhat surprisingly, these participants who were low on the instrumental component actually worked harder when paired with an incapable partner than did the participants who were high on the instrumental component. Thus, it seems that people who do not subscribe to the instrumental value of work are willing to compensate for a capability deficit, perhaps in order to gain the immediate incentives for high production. That is, for them, work may not lead invariably to rewards or be rewarding in itself but, when benefits are directly tied to collective production, they will compensate for less capable coworkers.

As predicted, participants who endorsed the equity principle were affected by the sucker manipulations. If their partner provided the impression that the participant could become the sucker, those who reported a preference for equity over equality reduced their effort considerably. In comparison, when they thought their team partner was less capable at the task, they exerted extra effort to compensate for their partner's deficits. Apparently it matters for people endorsing the equity principle why a coworker's contributions are subpar. If poor performance is due to a lack of ability, they almost appear to act according to the principle that input should be proportional to individual resources or ability. If they do not have any reason to believe that resources or abilities are disproportionate, they are sensitive to the subpar contributions of their partner and exert less effort. People who are more likely to endorse the equality norm do not seem to be affected by the reason for their partner's lesser input. If it appears to be lack of motivation or skill, it does not seem to affect them. They do not endorse the equity norm, and consequently, it seems that they do not experience any danger of becoming a sucker in the light of a violation of such a norm.

People who see hard work as an ethical marker also react to the apparent reasons that a coworker is performing poorly. Participants who believed in the ethical value of work were affected by the apparent cause of their partners' inferior contributions to the collective product. They, like equity endorsers seemed willing to compensate for lack of ability. However, they reduced their input when the partner was loafing. Thus, the ethical value that people see in work is not simply self-focused (i.e. 'If I work hard, I am good') but also other-focused (i.e. 'Lazy people are bad'). In other words, people who believe in the ethical value of work have a broader moral concern. When they are working with somebody who does not seem to spend much effort on the task, they are not willing to compensate for the other's lack of effort and, in the spirit of defending their moral claim, are prepared to forego part of their reward. Hence defending their moral claim seems more important than the external reward. People who do not believe in the ethical value of work, have less of a mission to defend some ethical principle, and hence do not appear to experience great psychological costs if another person might free-ride on their effort. Consequently they exerted the same effort, no matter whether the other person was incapable or not motivated.

Contrary to our predictions, the global PWE measure did not moderate the free-rider effect. Moreover, the free rider effect was only weakly 
related to the belief in the instrumental value of work. The trends suggest that people who believe in the notion that work should and will pay off did not take advantage of the possibility to free-ride on somebody else's effort. They worked equally hard when working alone and when working with another when contributions were not identifiable. Participants who believed to a lesser extent in the instrumental value of work were affected by the social context. When it needed their individual effort to get the reward they worked much harder, compared to the situation in which they could free-ride on somebody else's effort.

In sum, neither the sucker effect nor the freerider effect was moderated by the global construct of PWE. However the sucker-effect seemed to be moderated in different ways by the three components of the PWE, namely the belief in the ethical value of work, the belief in the instrumental value of work and the endorsement of the equity principle. The free-rider effect, on the other hand, seems to be only marginally moderated by the belief in the instrumental value of work.

Sucker and free-rider effects seem to be qualitatively different motivation losses in group performance. The sucker-effect is moderated by beliefs about the instrumental and ethical value of work and preferences for equity, whereas these components tells us less about who is likely to free-ride. One potentially contributing difference between avoiding being the sucker and freeriding is that avoiding the sucker role is a reaction to the behavior, anticipated or actual, of another person. In the experimental manipulation of the sucker-effect, the other person is giving the impression that he is lowering their input because he does not feel like working hard. Consequently the participant sees the danger that he might be exploited, and the psychological cost of exploitation is higher than foregoing part of the monetary reward for high productivity. But these psychological costs are not experienced by everybody alike. More specifically, it is subject to individual differences that are bundled in the PWE construct. A high belief in the instrumental value of work makes you immune to the suckereffect. Thus, instrumental value seems to be a more self-focused belief in the long-range benefits of working hard and thus less responsive to the social context. A strong endorsement of the equity principle makes one particularly vulnerable to the sucker-effect. Seemingly, the psychological costs of exploitation are perceived as high by people who believe in equity, and thus they avoid being the sucker. Interestingly a strong belief in the ethical value of work also makes one especially vulnerable to the sucker effect, suggesting that the cost of compensating for another's laziness is too costly.

The free-rider effect does not seem to be affected so strongly by the PWE components. Although it appears that belief in the instrumental value of work may reduce free-riding, this evidence in our data is statistically weak. Moreover, we obtained no evidence that the ethical value and equity preference moderate freeriding. One possible reason is that people may not be aware of the reduction of effort that we label free-riding. If they are not aware that they are working less hard in a collective effort, their beliefs about the work and equity may not be relevant. Moreover, it is clear that motivation loss in a free-rider situation is less of an affective reaction than in a sucker effect condition. From a certain perspective, free-riding seems rational. That is, reducing effort in team situations after getting joint feedback that the team is doing well could be an adaptive approach to collective endeavors. In the long run, it is functional to save one's resources when they are apparently not needed for future endeavors when they may be needed. This strategy does not necessarily contradict the ethical value of work.

In conclusion, we examined individual differences in free-riding and sucker-effects in collective work. People who believe in equity and the ethical value of work are particularly sensitive to being the sucker and, thus, reduce their own effort rather than compensate for the laziness of a coworker. By comparison, people who believe that work should and will be rewarded in the long-run do not seem to react to being the sucker. There is also a tendency for these people who believe in the instrumental value of work to be less likely to free-ride. One implication is that belief in the instrumental value of work is 
a guide for one's own behavior: 'If I work hard, I will be rewarded'. In contrast, both the ethical component of PWE and the equity norm are prescriptions not only about how one should act but also how one should react to others' expenditures of effort in collective work.

\section{Acknowledgment}

This work was supported by a Grant from the DAAD (Deutscher Akademischer Austauschdienst) awarded to the first author.

We are grateful to Adrian Furnham for giving us every facility to run the experiment at the University College London. We are also grateful to John Wieber for acting as an excellent confederate.

\section{References}

Adams, J. S. (1965). Inequity in social exchange. In L. Berkowitz (Ed.), Advances in experimental social psychology (pp. 267-99). New York: Academic Press.

Antoni, C. H. (1994). [Teamwork in companies concepts, experiences, perspectives].Gruppenarbeit in Unternehmen - Konzepte, Erfahrungen, Perspektiven. Weinheim: Psychologie Verlags Union.

Arnscheid, R., Diehl, M., \& Stroebe, W. (1997). [Lack of motivation in groups: An empirical test of a theoretical integration]. Motivationsverluste in Gruppen. Ein empirischer Test einer theoretischen Integration. Zeitschrift fuer Sozialpsychologie, 28, 241-250.

Blood, M. (1969). Work values and job satisfaction. Journal of Applied Psychology, 53, 456-459.

Brickenkamp, R. (1994). [Test d2-attention speed test]. Test d2 Aufmerksamkeits-Belastungs-Test. 8. Auflage (1. Auflage: 1962) Göttingen: Hogrefe Verlag für Psychologie.

Buchholz, R. (1976). Measurement of beliefs. Human Relations, 29, 1177-1188.

Cacioppo, J. T., \& Petty, R. E. (1982). The need for cognition. Journal of Personality and Social Psychology, 42, 116-131.

Furnham, A. (1990a). The Protestant work ethic. New York: Routledge.

Furnham, A. (1990b). A content, correlational, and factor analytic study of seven questionnaire measures of the Protestant Work Ethic. Human Relations, 43, 383-399.
Goldstein, B., \& Eichhorn, R. (1961). The changing Protestant ethic: Rural patterns in health, work and leisure. American Sociological Review, 26, 557-565.

Greenberg, J. (1978). Equity, equality, and the Protestant Ethic: Allocating rewards following fair and unfair competition. Journal of Experimental Social Psychology, 14, 217-226.

Hammond, P., \& Williams, K. (1976). Protestant ethic thesis: Social psychological assessment. Social Forces, 54, 579-589.

Harkins, S., \& Jackson, J. (1985). The role of evaluation in eliminating social loafing. Personality and Social Psychology Bulletin, 11, 457-465.

Harkins, S., \& Szymanski, K. (1989). Social loafing and group evaluation. Journal of Personality and Social Psychology, 56, 934-941.

Hart, J. W., Karau, S. J., Stasson, M. F., \& Kerr, N. A. (2004). Achievement motivation, expected coworker performance, and collective task motivation: Working hard or hardly working. Journal of Applied Social Psychology, 34, 984-1000.

Heaven, P. (1989). Structure and personality correlates of the Protestant Work Ethic among women. Personality and Individual Differences, 10, 101-104.

Ho, R. (1984). Adherence to Protestant Work Ethic values and helping judgments towards the unemployed. Unpublished paper.

Ho, R., \& Lloyd, J. (1984). Development of an Australian work ethic scale. Australian Psychology, 19, 321-332.

Hogan, R., \& Blake, R. J. (1996). Vocational interests: Matching self-concept with the work environment. In K. R. Murphy (Ed.), Individual differences and behavior in organizations. San Francisco: Jossey-Bass.

Homans, G. C. (1958). Human behavior as exchange. American Journal of Sociology, 63, 597-606.

Homans, G. C. (1961). Social behavior: Its elementary forms. New York: Harcourt, Brace \& World.

Ingham, A. G., Levinger, G., Graves, J., \& Peckham, V. (1974). The Ringelmann effect: Studies of group size and group performance. Journal of Experimental Social Psychology, 10, 371-384. 
Karau, S. J., \& Williams, K. D. (1993). Social loafing: A meta-analytic review and theoretical integration. Journal of Personality and Social Psychology, 65, 681-706.

Kerr, N. (1983). Motivation losses in small groups: A social dilemma analysis. Journal of Personality and Social Psychology, 45, 819-828.

Kerr, N., \& Brunn, S. (1983). Dispensability of member effort and group motivation losses: Free rider-effects. Journal of Personality and Social Psychology, 44, 78-94.

Kravitz, M., \& Martin, B. (1986). Ringelmann rediscovered. The original article. Journal of Personality and Social Psychology, 50, 936-941.

Latane, B., Williams, K., \& Harkins, S. (1979). Many hands make light the work: The causes and consequences of social loafing. Journal of Personality and Social Psychology, 37, 823-832.

Lied, T., \& Pritchard, R. (1976). Relationship between personality variables and components of the expecting valence model. Journal of Applied Psychology, 61, 463-467.

McClelland, D. C. (1961). The achieving society. New York: Van Nostrand.

Mirels, H., \& Garrett, J. (1971). The Protestant ethic as a personality variable. Journal of Consulting and Clinical Psychology, 36, 40-44.

Moede, W. (1927). [Introduction to performance psychology]. Die Richtlinien der Leistungspsychologie. Industrielle Psychotechnik, 4, 193-209.

Orbell, J., \& Dawes, R. (1981). Social dilemmas. In G. Stephenson \& J. H. Davis (Eds.), Progress in applied social psychology (Vol. 1). Chichester, UK: Wiley.

Ray, J. (1982). The Protestant ethic in Australia. Journal of Social Psychology, 116, 127-138.

Shepperd, J. A. (1993). Productivity loss in performance groups: A motivation analysis. Psychological Bulletin, 113, 67-81.

Shepperd, J. A., \& Taylor, K. M. (1999). Social loafing and expectancy-value theory. Personality and Social Psychology Bulletin, 25, 1147-1158.

Smith, B. N., Kerr, N. A., Markus, M. J., \& Stasson, M. F. (2001). Individual differences in social loafing: Need for cognition as a motivator in collective performance. Group Dynamics, Theory, Research, and Practice, 5, 150-158.

Steiner, I. D. (1972). Group process and group Productivity. New York: Academic Press.

Szymanski, K., \& Harkins, S. (1987). Social loafing and self-evaluation with a social standard.
Journal of Personality and Social Psychology, 53, 891-897.

Walster, E., Berscheid, E., \& Walster, G. W. (1973). New directions in equity research. Journal of Social and Personality Psychology, 25, 151-176.

Weber, M. (1905). Die protestantische Ethik und der 'Geist' des Kapitalismus. [The Protestant Ethic and the Sprit of Capitalism]. Archiv für Sozialwissenschaft und Sozialpolitik, 20, 1-54.

Paper received 29 September 2005; revised version accepted 14 June 2007.

\section{Biographical notes}

SUSANNE ABELE is now at Miami University, holding a visiting assistant research professorship. Prior to that she held positions at the Rotterdam School of Management at Erasmus University Rotterdam, as well as the University of Mannheim, Germany. She also worked as a consultant for a behavioral finance consultancy in Frankfurt, Germany. Her research interests comprise information processing in interdependent decision-making, basic processes in tacit forms of coordination, and the effects of person variables on social interaction.

MICHAEL DIEHL is a professor of personality and social psychology at the University of Tuebingen. His research interests are intra and intergroup processes, social-cognitive predictors of behavior, as well as effects of person variables on social psychological processes.

\section{Appendix}

Items with high loadings on the first factor (Ethical Factor):

1. Most people spend too much time in unprofitable amusement (Mirels \& Garrett, 1971)

2. Our society would have fewer problems if people had less leisure time (Mirels \& Garrett, 1971)

3. Most people who don't succeed in life are just plain lazy (Mirels \& Garrett, 1971)

4. A self-made person is likely to be more ethical than a person born to wealth (Mirels \& Garrett, 1971)

5. People should have more leisure time to spend in relaxation $(r)^{1}$ (Mirels \& Garrett, 1971) 
6. Life would be more meaningful if we had more leisure time (r) (Mirels \& Garrett, 1971)

Items with high loadings on the second factor (Instrumental Factor):

1. Hard work is not a key to success (r) (Ho, 1984)

2. People who work deserve success (Ho, 1984)

3 . There are few satisfactions equal to the realization that one has done one's best at a job (Mirels \& Garrett, 1971)

4. By working hard an individual can overcome most obstacles that life presents and make his or her own way in the world (Ho, 1984)

5. Nothing is impossible if you work hard enough (Ho, 1984)

6. If you work hard you will succeed (Ho, 1984)

7. The person who can approach an unpleasant task with enthusiasm is the one who gets ahead (Mirels \& Garrett, 1971)

8. Hard work is fulfilling in itself (Ho, 1984)
9. You should be best at what you do (Ho, 1984)

Items with high loadings on the third factor (Equity Factor):

1. When a task is completed by a team there is nothing wrong with distributing the reward equally regardless of unequal input $(r)$

2. The relative input of each team-member does not necessarily provide a legitimate basis for claiming differential rewards ( $r$ )

3. Rewards should be distributed to persons in direct proportion to their inputs (i.e. their relative contributions)

4. The trouble with giving people equal rewards for work is that they very rarely work equally hard

5. If people work together on a task it is very important that the reward is distributed in proportion to the effort each puts in

${ }^{1}$ (r) means that the scoring of the item is reversed. 